\title{
Allergie hat Konjunktur
}

D er saisonale Pollenflug hat mit Macht eingesetzt und belastet unsere Patienten, der Kongress der „European Academy of Allergology and Clinical Immunology" war ein Großereignis, das Mitte Mai mehr als 4000 Allergologen in Berlin zusammenführte, und in den Laienmedien sind allergologische Themen „in“!

Die Fülle des auf dem Berliner Kongress Präsentierten war überwältigend, die Darstellung systematisch aufbereiteten Wissens in Übersichtsreferaten und die Mitteilungen hochaktueller Forschungsergebnisse zeigten, dass sich die Allergologie dynamisch und fruchtbar weiterentwickelt. Zwar ist, insbesondere was die Frage nach der Ursache und nach der Pathophysiologie allergischer Erkrankungen anbelangt, noch viel $\mathrm{zu}$ tun. Ohne Zweifel kön"Was Ursache und nen aber auf der Pathophysiologie an- Grundlage des heubelangt, gibt es noch te Bekannten fast viel zu tun" alle Allergiekranken so behandelt werden, dass sie wesentlich gebessert oder gar symptomfrei sind!

Leider ist aber ein solch ideales Ergebnis des Patientenmanagements in der klinischen Wirklichkeit immer noch eher die Ausnahme als die Regel. Zwar ist allergologisches Wissen in hoher Qualität verfügbar, es ist jedoch nicht ausreichend verbreitet beziehungsweise wird oft nicht konsequent angewandt. Dafür sind nicht nur die bekannten strukturellen und finanziellen Restriktionen verantwortlich!

Wie soll sich der Patient orientieren, wenn er in der Laienpresse liest, dass doch alles von der Psyche kommt, Katzenhaltung vor Allergien schützt oder eine Kindheit im Kuhstall die beste Allergie-Prophylaxe ist? Als naturwissenschaftlich denkende Ärzte können wir

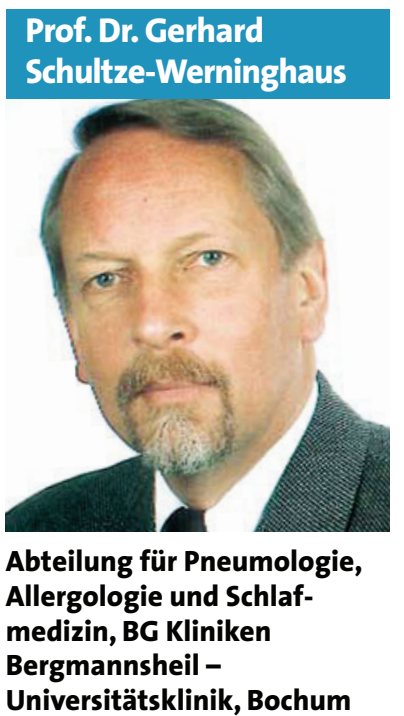

zur Qualitätssicherung der Patientenversorgung ist dabei ein sehr wichtiger Punkt, zahlreiche Positionspapaiere, Leitlinien und Stellungnahmen sind in ALLERGO JOURNAL schon erschienen. Die „Leitlinie für die Durchführung bronchialer Provokationstests mit Allergenen" finden Sie in diesem Heft (Seite 193).

Ein neuer, vielversprechender Ansatz in der Diagnostik bei atopischem Ekzem ist der Atopie-PatchTest, bei dem Protein-Allergene in einem dem Epikutan-

solches einordnen, der Laie aber ist verwirrt. „Dreckige Kinder leben gesünder" titelte eine bekannte Boulevardzeitung als Aufmacher: Die hypothetische Interpretation epidemiologischer Forschungsergebnisse - Aufenthalt von Säuglingen im Kuhstall ist mit geringerer Allergiehäufigkeit assoziiert - mutiert unverzüglich zur (scheinbar) praktischen Handlungsanleitung. Wie könnte der gesunde Dreck für unsere Kinder aussehen? Ganz allgemein weniger Sauberkeit, mehr Keime und mehr Infektionen sind sicher keine sinnvolle Prophylaxe. Manche Kinder bleiben aus solchen Gründen schon ungeimpft! Lieber tot als allergisch?

Patentlösungen sind nicht zu erwarten. Der Fortschritt sprintet nicht, sondern muss sorgfältig erarbeitet werden. Systematische Wissensaufbereitung

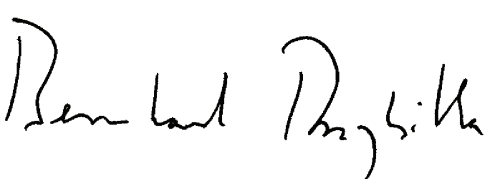

Prof. Dr. B. Przybilla test ähnlichen Verfahren auf die Haut aufgebracht wer-

den. Der Atopie- „Manche Kinder bleiben Patch-Test kann schon ungeimpft! Lieber nach sorgfältiger tot als allergisch?" methodischer Auf-

bereitung Eingang in die klinische Praxis finden (Seite 201).

Umwelteinwirkungen können den Menschen über sehr unterschiedliche Pathomechanismen krank machen: Zecken übertragen Infektionserreger, sondern Toxine $\mathrm{ab}$ und verursachen allergische Reaktionen (Seite 215).

Sind bald alle Menschen atopisch? Mitte der 90er Jahre waren 63,6\% der Berliner Medizinstudenten atopisch, Mitte der 80er Jahre waren es nur 36,3\% (Seite 210). Diese Entwicklung ist dramatisch und regt zu Spekulationen an!

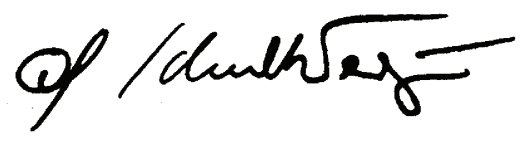

Prof. Dr. G. Schultze-Werninghaus 